\title{
PERIPARTUM CARDIOMYOPATHY: A MANAGEMENT DILEMMA
}

Niranjan Kumar Verma ${ }^{1}$

\section{HOW TO CITE THIS ARTICLE:}

Niranjan Kumar Verma. "Peripartum Cardiomyopathy: A Management Dilemma". Journal of Evolution of Medical and Dental Sciences 2014; Vol. 3, Issue 28, July 14; Page: 7945-7949,

DOI: $10.14260 /$ jemds/2014/2994

ABSTRACT: Peripartum cardiomyopathy (PPCM) is a form of dilated cardiomyopathy of unclear etiology, affecting women without pre-existing cardiac diseases, during the last month of pregnancy or up to five postpartum months ${ }^{1}$ As with other form of dilated cardiomyopathies, PPCM involves the systolic dysfunction of the heart with a decrease in Left Ventricular Ejection Fraction (LVEF) <40, associated with congestive heart failure and with an increased risk of supra ventricular or ventricular arrhythmias, thromboembolism and even sudden cardiac death. PPCM is diagnosed by exclusion, where the patient has no history of previous heart disease, coincides with the pregnancy period (one month pre-operative to five months post- operative), and where no other possible cause of heart failure present. Diagnosis of Peripartum cardiomyopathy is a dilemma for the obstetricians, physicians, cardiologists, and the general physicians, as most of these patients are hurriedly diagnosed and treated first as a case of Left Ventricular Failure (LVF) of some cardiac origin. Specific treatment is started late or not at all. So, relapses are very common with the treatment line of Left Ventricular Failure of cardiac origin only without any specific treatment and no precautions taken, thereafter. Although the exact cause of PPCM is unknown, yet (a) some cardio tropic virus (b) immune system dysfunction8, (c) genetic factors 1, (d) deficiency of micro-nutrients or trace elements (e) some cardio-toxins may serve as a trigger to malfunction of immune system that may be responsible in the development of PPCM. Recently two cases of PPCM were transferred to our ICU from the obstetrics and gynecology department immediately after deliveries for acute left ventricular failure in quick succession and were diagnosed as PPCM and successfully managed with Diuretic, ACE inhibitor, Beta blocker and Nitrates with mechanical ventilation. After discharge from the hospital they are being followed up and are put on Hydralazine with ACE inhibitor and beta blocker since last three months and they are reported doing well.

KEYWORDS: LVF (Left Ventricular Failure), LVEF (Left Ventricular Ejection Fraction), BPN (Brain Natriuretic Peptide).

\section{ETIOLOGY:}

1. Abnormal prolactin metabolism. ${ }^{[2,3,12]}$

2. Physiological stress of pregnancy. ${ }^{13}$

3. Auto-immune factors ${ }^{7}$

4. Viral myocarditis ${ }^{7}$

5. Nutritional deficiencies ${ }^{13}$

6. Prolonged Tocolysis ${ }^{15}$ 


\section{ORIGINAL ARTICLE}

\section{CONTRIBUTING RISK FACTORS ${ }^{1}$ :}

1. Elderly para.

2. Multi para.

3. Multiple gestations.

4. Anemia.

5. Malnutrition.

6. Tobacco user.

7. Hypertensive manifestations (Pre-eclampsia or eclampsia may be associated with PPCM in $29-46 \%) \cdot[15,17]$

8. African descents ${ }^{13}$

\section{SIGNS and SYMPTOMS:}

\section{The affection period: - Ratio between different Peripartum months is as follows ${ }^{17}$ :}

Last month of pregnancy: $1^{\text {st }}$ month of pregnancy: $2^{\text {nd }}$ to $5^{\text {th }}$ postpartum $=7 \%: 75 \%: 18 \%$

Although some patients may have complaints of Dyspnea particularly on exertion, orthopnea, edema lower limbs but unfortunately these symptoms are common in normal women in last month and immediate postpartum months of pregnancy, making the early diagnosis of development of PPCM challenging.

Diagnosis is delayed by more one week in $48 \%$ of cases and more than a month in $30 \%$ cases as the primary symptoms are attributed to normal pregnancies. Even some cases are misdiagnosed and treated as a case of Pneumonia. Actually, almost all the cases are diagnosed by the time the time patients develop advanced symptoms.

Signs of volume over load as Pulmonary rales, Tachypnea, Tachycardia, Distended neck veins, Pathological S3 or S4 heart sounds, and lower limb edema will be there.

ECG may show following changes: -Sinus tachycardia, T-Wave abnormality, ST - T abnormality and Left ventricular hypertrophy.

$\mathrm{X}$-Ray chest may show cardiomegaly, pulmonary venous congestion and pleural effusion.

Echocardiography shows mean baseline LVEF $<31 \%$, Left ventricular dilatation and presence of Left Ventricular thrombus. ${ }^{11}$

This inadvertent delay is the cause of some patient admitting with abnormal presentations like: - Peripheral, cerebral or hepatic thromboembolic phenomenon as pulmonary embolism, ${ }^{14}$ limb ischemia, myocardial infarction, cerebral stroke ${ }^{6}$ or Acute hepatic failure. One case report is of patient being diagnosed as Acute Hepatic failure and was being prepared for Liver transplant operation. Luckily an echocardiography was performed which revealed the heart failure being the primary cause of hepatic involvement. Patient was then treated with conventional heart failure medications and the patient survived and recovered completely.

Following is a screening tool developed by James D. Fett ${ }^{13}$, which is useful in diagnosing PPCM in early stages and for starting advanced diagnostic tests:

1. Orthopnea (none - 0 point, needs elevation of head - 1 point, need to elevate upper part of body by $45^{*}$ - 2 points).

2. Dyspnea (none -0 , on climbing 8 steps -1 , on level walking -2 ).

3. Unexplained cough (none -0 , night time -1 , always -2 ). 


\section{ORIGINAL ARTICLE}

4. Pitting edema lower limb (none -0 , below knee -1 , both upper and lower limbs with face -2 )

5. Excess unexpected weight gain during last month of pregnancy (under one $\mathrm{Kg} / \mathrm{month}-0,1-2$ $\mathrm{Kg} /$ month - 1, over $2 \mathrm{Kg} /$ month - 2).

6. Palpitation (none -0 , when lying down -1 , always -2 ).

\section{Scoring and action to be taken: ${ }^{13}$}

- 0 to 2 points - Low risk - Patient to be put on continuous observation.

- 3 to 4 points - Mild risk - Blood B.P.N and C.R.P when raised then go for echocardiography.

- More than 5 points - High risk -High Blood B.P.N, C.R.P and positive echocardiography ${ }^{11}$ and patient to be admitted to I.C.U.

Brain Natriuretic peptide(BNP)- BPN level is approximately twice as high in pregnant verses Non pregnant women but this elevated level remains constant throughout the entire pregnancy period and 5-6 months postpartum.

In non-pregnant ladies - BPN is about $50 \mathrm{pg}$. $/ \mathrm{ml}$.

In normal pregnancy - BPN is about $100 \mathrm{pg}$. $/ \mathrm{ml}$, throughout.

In PPCM - BPN level becomes 1258 pg. /ml or even more. ${ }^{4}$

Thus a mild elevation in BPN is expected with normal pregnancies, a much higher level is diagnostic of PPCM. ${ }^{5}$

PROLACTIN AND PPCM: Prolactin is liberated from anterior pituitary in response to: (a) Physiological stress (b) Nipple stimulation by breast feedings.

Level of Prolactin is increased in normal pregnancy and peaks at the time of delivery. The proposed mechanism is unbalanced oxidative stress leading to activation of "Protease Cathepsin - D", which acts to clear full length $23 \mathrm{kDa}$ Prolactin to an angiostatic and Pro-apoptotic 16kDa Prolactin.[2,12] It is this $16 \mathrm{kDa}$ Prolactin which exerts negative systemic effects on the endothelium of systemic and cardiac vasculatures and causes myocardial dysfunction leading to PPCM. ${ }^{2}$

A lack of antioxidant enzyme "Magnesium-Sodium-Dismutase (MnSoD)" leads to increased free oxygen radical production in the heart muscle. This leads to higher oxidative stress and in turn to a fatal cleavage of Prolactin into a Pro-apoptic and anti angio genetic $16 \mathrm{kDa}$ sub form.

Blockade of Prolactin with BROMOCRIPTIN (A Dopamine D2 receptor agonist) has been shown to prevent PPCM in experimental modules. ${ }^{7}$

Immunological Factors and PPCM: Serum level of "Pro-Inflammatory-Cytokine-Tumor-NecrosisFactor (TNF)" is raised ${ }^{[4,5]}$ and treatment with Pentoxyphyline (an inhibitor of TNF production) may have beneficial effect on the outcome of PPCM.

Management of PPCM: The clinical course of PPCM resembles that of a dilated cardiomyopathy with the typical signs of severe cardiac failure, followings may be tried accordingly:

- A.C.E. inhibitors. ${ }^{9,16}$

- Diuretic (to remove excess fluid).9,16

- Aldosterone antagonist.9,16

- Beta blockers in low dose.9,16 
- Digitalis (to strengthen the heart pumping activity).9,16

- Inotropic support.

- Pentoxyphyline ${ }^{5}$

- Bromocriptine $^{3}$

- Mechanical ventilatoy support.

- Intra-aortic-balloon-pump-counter pulsation..$^{10}$

- Even heart transplantation ${ }^{10}$

- For thromboembolism - Enoxaparin 20 mg twice daily 14-21 days.

- For cardiac dysrhythmia and prevention of sudden cardiac deaths - Implantable Biventricular Cardioverter ${ }^{10}$.

- $\quad$ Breast feeding is totally prohibited. ${ }^{16}$

Prognosis and Conclusion: With early diagnosis and newer conventional left ventricular failure treatments, survival rate is $>98 \%$ with recovery of heart function (LVEF> 55\%). The treatment should be continued for $>6$ months after full recovery for fear of relapses. ${ }^{18}$ Once fully recovered, if there is no subsequent pregnancy ${ }^{8}$, the possibility of relapses and recurrence of heart failure is minimal. ${ }^{17}$

\section{REFERENCES:}

1. Sliwa K. Fett J, Elkayam U. Peripartum cardiomyopathy. Lancet. 2006; 368: 2354-2355. [Pub Med].

2. Hilfiker-Kleiner D, Kaminski K, Podewski E, et al. A cathepsin D-cleaved $16 \mathrm{kDa}$ form of prolactin mediates postpartum cardiomyopathy. Cell. 2007; 128: 589-600. [Pub Med].

3. Hilfiker-Kleiner D, Meyer GP, Schrieffer E, et al. Recovery from postpartum cardiomyopathy in 2 patients by blocking prolactin release with Bromocriptine. J Am Coll Cardiol, 2007; 50: 23542355.[Pub Med].

4. Sliwa K, Forster 0, and Libhaber E, et al. Peripartum cardiomyopathy: inflammatory marker as predictors of outcome in 100 prospectively studied patients. Eur Heart J. 2006; 27: 441-446.

5. Sliwa K, Skudicky D, Candy G, Bergmann A, Hopley M, Sareli P. The addition of Pentoxyphyline to conventional therapy improves outcome in patients with Peripartum cardiomyopathy.

6. Witling AG, Matter F, Saibai BM. Postpartum stroke: a twenty year experience. Am J obst Gynecol. 2000; 183: 83-88. [Pub Med].

7. Sliwa K, Forster O, Zhanje F, Candy G, Kachope J, Essop R. Outcome of subsequent pregnancy in patients with documented Peripartum cardiomyopathy. Am J Cardiol. 2004; 93(11)1441-1443. [Pub Med].

8. Fett JD, Fristoe KL, Welsh SN. Risk of heart failure relapse in subsequent pregnancy among Peripartum cardiomyopathy mothers. Int J Obstet. 2010; 109(1): 34-36. [Pub Med].

9. Felker GM, Jaeger CJ, Klodas E, et al Myocarditis and long term survival in Peripartum cardiomyopathy. Am Heart J. 2000; 140(5): 785-791. [Pub Med].

10. Desai AS, Fang JC, Misael WH, Baughman KL. Implantable defibrillators for the prevention of mortality in patients with non-ischemic cardiomyopathy: a mate analysis of randomized controlled trials. JAMA.2004; 292(23): 2874-2879. [Pub Med]. 
11. Chapa JB, Heiberger HB, Weinert L, Decara J, Lang RM, Hibbard JU. Prognostic value of echocardiography in Peripartum cardiomyopathy. Obstet Gynecol.2005; 105(6): 1303-1308. [Pub Med].

12. Yamac H, Bultmann I, Sliwa K, Hilfiker-Kleiner D. Prolactin: a new therapeutic target in Peripartum cardiomyopathy. Heart. 2010; 96(17): 1352-1357 [Pub Med].

13. Fett JD. "Understanding Peripartum cardiomyopathy”. Int J Cardiol, 2008; 130(1): 1-2.

14. Lasinska-Kowara M, Dudziak M, Suchorzewska J.(September 2001) "Two cases of postpartum cardiomyopathy initially misdiagnosed for pulmonary embolism". Can J Anaesth 2001: 48(8): 773-777.

15. Desai D, Moodley J, Naidoo D. Peripartum cardiomyopathy: experiences at King Edward VIII Hospital, Durban, South Africa and a review of the literature. Trop Doct. 1995; 25 (3): 118-123.

16. Amos AM, Jaber WA, Russell SD.(September 2006), Improved outcome in Peripartum cardiomyopathy with contemporary treatments". AHeart J. 2006: 152(3).509-13.

17. Elkayam U, Tummala PP, Rao K, et al. "Maternal and fetal outcomes of subsequent pregnancies in women with Peripartum cardiomyopathy". N. Eng J. Med. 2001; 344(21): 1567-71.

18. Pearson GD, Veille JC, Rahimtoola S, et al. "Peripartum cardiomyopathy, recommendation and review workshop, National Heart Lung and Blood institute and office of rare diseases(National institute of health)"March 2000), JAMA.283(9): 1183-88.

\section{AUTHORS:}

1. Niranjan Kumar Verma

\section{PARTICULARS OF CONTRIBUTORS:}

1. Associate Professor and HOD, Department of Anaesthesiology, J. L. N. Medical College, Bhagalpur, Bihar.

\section{NAME ADDRESS EMAIL ID OF THE} CORRESPONDING AUTHOR:

Dr. Niranjan Kumar Verma, Associate Professor and HOD, Department of Anaesthesiology, J. L. N. Medical College, Bhagalpur-812001, Bihar Email: nkverma2001@yahoo.com

Date of Submission: 25/06/2014. Date of Peer Review: 26/06/2014. Date of Acceptance: 05/07/2014. Date of Publishing: 14/07/2014. 